\title{
Television: a way of distracting patients during sexual and reproductive healthcare procedures
}

\author{
Hannat Akintomide, ${ }^{1}$ Jagruti Doshi, ${ }^{2}$ Jo Power, ${ }^{3}$ Chris Wilkinson ${ }^{4}$
}

- Additional material is published online only. To view please visit the journal online (http://dx.doi.org/10.1136/jprhc2015-101289)

${ }^{1}$ Specialty Doctor, Department of Sexual and Reproductive Health, CNWL Camden Provider Services, Margaret Pyke Centre, London, UK ${ }^{2}$ Specialty Doctor, Sexual and Reproductive Health, CNWL Camden Provider Services, Margaret Pyke Centre, London, UK

${ }^{3}$ Consultant, Department of Sexual and Reproductive Health, CNWL Camden Provider Services, Margaret Pyke Centre, London, UK

${ }^{4}$ Consultant, Sexual and Reproductive Health, CNWL Camden Provider Services, Margaret Pyke Centre, London, UK

\section{Correspondence to} Dr H Akintomide, Specialty Doctor, Department of Sexual and Reproductive Health, CNWL Camden Provider Services, Margaret Pyke Centre, 44 Wicklow Street, London WC1X 9HL, UK; h.akintomide@nhs.net

Received 29 June 2015 Revised 22 December 2015 Accepted 30 December 2015 Published Online First

27 January 2016

\section{BACKGROUND}

The Margaret Pyke Centre is an integrated sexual health service with up to 500 attendances a week and 200 procedures performed per month. The majority of the procedures carried out in the service are related to the provision of intrauterine contraception (IUC).

Anxiety has been shown to contribute to higher levels of pain perceived during procedures such as IUC insertion. ${ }^{1}$ Distraction during the procedure may help in reducing anxiety and consequently pain. For example, during IUC insertion, verbal distraction, popularly referred to as 'verbal anaesthesia' or 'vocal local', can be provided by an assistant, or the patient could be advised to hold a small warm water bottle or chemical warming pack inside a disposable cover to the suprapubic region. ${ }^{2}$

We thought of a different way of distracting patients during procedures. Patients had previously reported that static pictures on the ceilings in our clinic rooms were helpful. As a result of a charitable donation, in September 2013 the service installed televisions (TVs) in three clinic rooms where procedures such as IUC insertions are performed. The aim was to give patients the choice to watch and/or listen to something during their procedures. TVs are already successfully used during dental procedures and paediatric phlebotomy, but their use has not been reported during procedures in sexual health.

\section{HOW DID WE GO ABOUT THE CHANGE?}

The service was changing sites and the opportunity was used to install a TV on the ceiling, directly above the examination couch in the rooms (figure 1). A policy on its use was agreed to ensure that staff work safely and patient care is not compromised. This included the TV's default setting being subtitles on and volume muted, that the staff remain vigilant and can converse with the patient throughout and that any changes to the TV's default setting should be agreed with the clinician performing the procedure. Patients can choose to have the TV switched off. Over 100 TV channels are available, including radio stations (e.g. for music). The service had previously installed TVs in its patient waiting areas and so already had an appropriate TV license.

We conducted surveys of staff and patients 2 months before and 8 months after the introduction of the TVs, using short semi-structured anonymous paper questionnaires (see online supplementary material). The questionnaires were made available in the most frequently used room with a TV. Staff included doctors, nurses and healthcare support workers (HCSWs) involved in the care of patients during procedures. Staff completed the questionnaires in their own time. Patients were offered the questionnaires to complete after their procedure and having left the clinic room. Participants were therefore self-selecting and only needed to answer those questions that applied to them. For this latter reason, denominators were not the same for all the questions as each denominator was determined by the number of responses to that question. Each survey period lasted 6 weeks, and the last survey was completed on 31 July 2014.

\section{WHAT DID PATIENTS THINK?}

Sixty-three patients participated in the survey conducted before the TVs were introduced, with over half $(57 \%, n=36)$ aged 25-34 years. When asked, "Do you think you would like to have a TV to watch or listen to during your
Doshi J, Power J, et al. J Fam Plann Reprod Health Care 2016;42:220-221. 


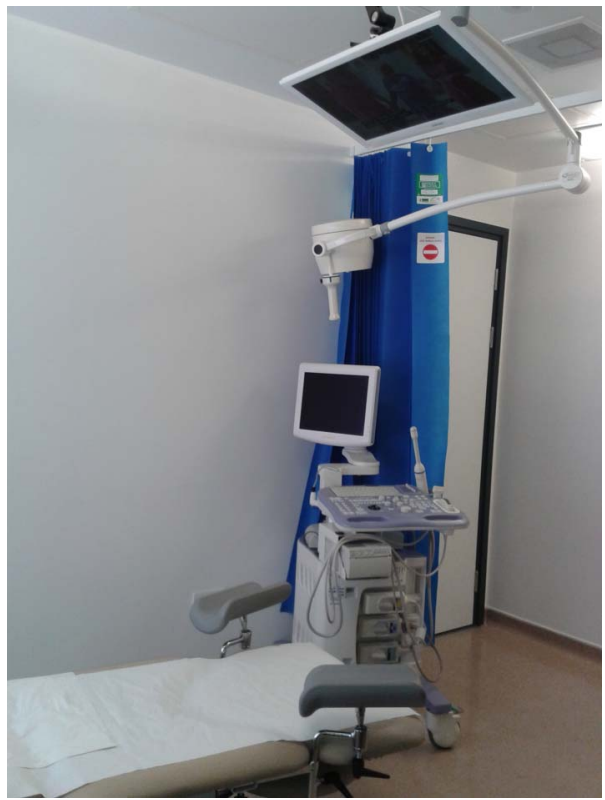

Figure 1 Clinic room with TV on the ceiling.

procedure?", $47 \%$ said yes, $40 \%$ said no and $13 \%$ were not sure $(n=30,25$, and 8 , respectively). Of those patients $(n=25)$ who thought they would not like to have a TV, 9 patients (14\%) said they preferred having someone to talk to or hold their hand as this helped them feel calm and more relaxed.

Forty-five patients completed the survey after the TVs had been installed. Of those offered the option of having a TV on during their procedure $(n=42), 90 \%$ $(n=38)$ accepted and were happy to have the TV to watch or listen to. Most patients $(92 \%, n=35)$ felt that the TV helped to distract them during the procedure, some $(68 \%, n=16)$ felt that it helped calm them and make them less anxious, and one patient commented that it was a source of conversation. Most patients (76\%, 31 of 41 respondents) were satisfied to watch the channel that was already on. Fifty-one per cent of 43 respondents $(n=22)$ preferred subtitles only, 9\% $(n=4)$ preferred audio only, while $44 \%(n=19)$ had no preference. Only three patients preferred to chat to the staff during the procedure which they found more calming.

\section{WHAT DID STAFF THINK BEFORE AND AFTER THE INTRODUCTION OF THE TVS?}

Thirty staff completed the survey conducted prior to TV installation. This included 7 doctors, 17 nurses and 6 HCSWs. Thirty-eight per cent of 29 respondents $(n=11)$ said they would like patients to watch TV during their procedure, 59\% $(n=17)$ were unsure, while only 1 disapproved. Seventy-six per cent of 29 respondents $(n=22)$ felt the TV would make patients less anxious. The majority $(40 \%, n=12)$ were also happy to offer the TV to all patients but felt it was ultimately the patient's choice.

Twenty-four staff completed the survey conducted after TV installation: 12 were doctors, 6 were nurses and 6 were HCSWs. Seventy-nine per cent $(n=19)$ routinely offered patients the option of having the TV on during their procedure because they felt it made patients less anxious and it was effective in distracting them. Most staff $(42 \%, n=10)$ felt daytime TV, a movie or sports was most suitable. One staff stated, "food and property shows tend to go down well". One staff felt it facilitated conversation with patients during their procedure. One staff stated that the TV was not as distracting as they initially thought it would be.

\section{WHAT ARE THE BENEFITS OF HAVING A TV?}

$\mathrm{TV}$ is an intervention that requires minimum effort, time or maintenance, and incurs a one off installation cost. The reaction of most patients when they see a TV on the ceiling after lying on the examination couch is one of pleasant surprise-" "You have a TV here!". Patients have the choice to watch TV during their procedure to reduce their anxiety. It provides a form of visual (passive) distraction in addition to the verbal (active) distraction that is available from the assistant. It also provides a topic for conversation but it can be turned off if the patient wishes.

\section{WHAT COULD BE POSSIBLE DISADVANTAGES?}

The focus still needs to be on the patient and the procedure. It is important that engagement with the patient is not prevented by the TV. There could be a small risk that if both the assistant and patient are focused on the TV there may be a delay in detecting an adverse event in the patient. However, we have had no adverse events related to the use of TVs. Choice of TV programme may be important as one patient suggested that the news channel could be problematic if it showed bad news. Also, despite it being a one off cost, the purchase of TVs and their installation is still an additional expense to the service.

\section{CONCLUSION/ADVICE TO OTHER SERVICES CONSIDERING SUCH CHANGE}

We have now had TVs to distract patients during sexual and reproductive healthcare procedures for nearly 2 years, and our experience has been positive. We recommend that other services consider having TVs available to their patients during sexual and reproductive healthcare procedures.

Acknowledgements We are grateful to the staff and patients who anonymously participated in the surveys reported.

Competing interests None declared.

Provenance and peer review Not commissioned; externally peer reviewed.

\section{REFERENCES}

1 Murty J. Use and effectiveness of oral analgesia when fitting an intrauterine device. J Fam Plann Reprod Health Care 2003;29:150-151.

2 Bahamondes L, Mansour D, Fiala C, et al. Practical advice for avoidance of pain associated with insertion of intrauterine contraceptives. J Fam Plann Reprod Health Care 2014;40:54-60. 